\title{
Safety, tolerability and appropriate use of nintedanib in idiopathic pulmonary fibrosis
}

Tamera Corte ${ }^{1,2^{*}}$, Francesco Bonella ${ }^{3}$, Bruno Crestani ${ }^{4}$, Maurits G. Demedts ${ }^{5}$, Luca Richeldi ${ }^{6}$, Carl Coeck , Katy Pelling ${ }^{8}$, Manuel Quaresma ${ }^{9}$ and Joseph A. Lasky ${ }^{10}$

\begin{abstract}
Background: Idiopathic pulmonary fibrosis (IPF) is a progressive disease characterised by dyspnea and loss of lung function.

Methods: Using pooled data from the replicate, randomized, 52-week, placebo-controlled INPULSIS trials, we characterized the safety and tolerability of nintedanib $150 \mathrm{mg}$ twice daily in patients with IPF and described how adverse events were managed during these trials.

Results: One thousand and sixty- one patients were treated (nintedanib 638; placebo 423). Higher proportions of patients in the nintedanib group than the placebo group had $\geq 1$ dose reduction to $100 \mathrm{mg}$ bid $(27.9 \%$ versus $3.8 \%$ ) or treatment interruption (23.7\% versus $9.9 \%$ ). Adverse events led to permanent treatment discontinuation in $19.3 \%$ and $13.0 \%$ of patients in the nintedanib and placebo groups, respectively. Diarrhea was the most frequent adverse event, reported in $62.4 \%$ of patients in the nintedanib group versus $18.4 \%$ in the placebo group; however, only $4.4 \%$ of nintedanib-treated patients discontinued trial medication prematurely due to diarrhea. Monitoring of liver enzymes before and periodically during nintedanib treatment was recommended so that liver enzyme elevations could be managed through dose reduction or treatment interruption.
\end{abstract}

Conclusion: Nintedanib had a manageable safety and tolerability profile in patients with IPF. Recommendations for adverse event management minimized permanent treatment discontinuations in the INPULSIS ${ }^{\circ}$ trials.

Trial registration: clinicaltrials.gov NCT01335464 and NCT01335477

\section{Background}

Idiopathic pulmonary fibrosis (IPF) is a progressive, fibrosing interstitial pneumonia, occurring primarily in the elderly population, which is characterized by increasing dyspnea and loss of lung function [1-3]. Patients with IPF have impaired quality of life and reduced exercise tolerance [4]. IPF is ultimately fatal, with a median survival time of only $2-3$ years from diagnosis [3].

Our evolving understanding of the pathophysiology of IPF suggests complex interplay between multiple pathways. Protein tyrosine kinases are known to play a key role in intracellular signaling pathways involved in the pathogenesis of lung fibrosis [5-7]. Nintedanib is an intracellular inhibitor of tyrosine kinases, including the receptors for the fibroblast growth factor (FGF), platelet-

\footnotetext{
* Correspondence: tameracorte@mac.com

${ }^{1}$ Royal Prince Alfred Hospital, Camperdown, New South Wales, Australia

¿University of Sydney, Sydney, New South Wales, Australia

Full list of author information is available at the end of the article
}

derived growth factor (PDGF) and vascular endothelial growth factor (VEGF) $[8,9]$. In preclinical studies nintedanib interfered with processes associated with fibrosis including fibroblast proliferation, migration and differentiation and was associated with reduced secretion of extracellular matrix and reduced lung inflammation [9].

The efficacy and safety of nintedanib as a treatment for IPF have been studied in the Phase II, 52-week, TOMORROW trial [10] and in the two replicate randomized, placebo-controlled, 52-week Phase III INPULSIS trials $[11,12]$. Results from the TOMORROW trial, which involved 432 patients with IPF, suggested that compared with placebo, treatment with nintedanib $150 \mathrm{mg}$ twice daily (bid) was associated with a reduced annual decline in forced vital capacity (FVC), fewer acute exacerbations, and preservation of health-related quality of life, assessed using the St George's Respiratory Questionnaire (SGRQ) [10]. In both INPULSIS trials, 
the primary endpoint of the annual rate of decline in FVC was significantly reduced by approximately $50 \%$ in the nintedanib group compared with placebo, consistent with a slowing of disease progression. The adjusted annual rate of decline in FVC was $-114.7 \mathrm{~mL} /$ year with nintedanib versus $-239.9 \mathrm{~mL} /$ year with placebo (a difference of $125.3 \mathrm{~mL} /$ year [ $95 \%$ confidence interval (CI): 77.7, 172.8]; $p<0.001$ ) in INPULSIS -1 and $-113.6 \mathrm{~mL} /$ year with nintedanib versus $-207.3 \mathrm{~mL} /$ year with placebo (a difference of $93.7 \mathrm{~mL} /$ year [95 \% CI: 44.8, 142.7]; $p<0.001)$ in INPULSIS -2 [11]. In INPULSIS -2 , there was a significant difference in favor of nintedanib for time to first acute exacerbation and change from baseline in SGRQ total score, both over 52 weeks. However, in INPULSIS -1, no significant difference between groups was observed for either of these endpoints [11]. Gastrointestinal events, particularly diarrhea, were the most frequently reported adverse events in patients treated with nintedanib.

An analysis of pooled safety data from the two INPULSIS $^{\circ}$ trials was pre-specified. In this manuscript, we further characterize the safety and tolerability of nintedanib and describe how adverse events were reported and managed during these Phase III trials.

\section{Methods}

The INPULSIS ${ }^{\circ}$ trials, performed at 205 sites in 24 countries in the Americas, Europe, Asia and Australia, recruited a broad range of patients with IPF [11]. Patients with IPF aged $\geq 40$ years were eligible to participate if they had an FVC of $\geq 50 \%$ of predicted value and a diffusing capacity of the lung for carbon monoxide $\left(\mathrm{DL}_{\mathrm{CO}}\right)$ of $30-79 \%$ of predicted value. In the absence of a surgical lung biopsy, diagnosis of IPF required the presence of honeycombing and/or a combination of traction bronchiectasis and reticulation, without nodules or consolidation, on high-resolution computed tomography (HRCT), which was centrally reviewed. If available, surgical lung biopsies were centrally reviewed to confirm eligibility to enter the trials using a multidisciplinary approach. Patients with emphysema on HRCT were not excluded, but patients were required to have an $\mathrm{FEV}_{1} /$ FVC ratio of $\geq 0.7$. Concomitant therapy with prednisone $\leq 15 \mathrm{mg} /$ day, or the equivalent, was permitted if the dose had been stable for $\geq 8$ weeks before screening. Patients receiving other therapies for IPF, including pirfenidone, prednisone $>15 \mathrm{mg} /$ day, azathioprine, $\mathrm{N}$ acetylcysteine and any investigational treatments for IPF, were excluded. Patients with elevated hepatic enzymes (alanine aminotransferase [ALT] or aspartate aminotransferase [AST]) or bilirubin $>1.5 \mathrm{x}$ upper limit of normal (ULN) were excluded.

Eligible patients were randomized using a 3:2 ratio to receive nintedanib $150 \mathrm{mg}$ bid or placebo for 52 weeks, followed by a 4-week follow-up period. There was no requirement for dose titration on initiation of treatment. Treatment interruption and/or dose reduction from $150 \mathrm{mg}$ bid to $100 \mathrm{mg}$ bid were allowed for the management of adverse events. For patients who had a dose interruption, treatment could be reinstituted at a dose of $150 \mathrm{mg}$ bid or $100 \mathrm{mg}$ bid after resolution of the adverse event. After a dose reduction, the dose could be reescalated to $150 \mathrm{mg}$ bid. Specific recommendations were provided to the investigators for the management of diarrhea (Fig. 1) and hepatic enzyme elevations (Fig. 2).

For patients who had $>1$ treatment interruption, the duration of treatment interruption was calculated as total duration of all interruptions. Dose intensity was defined as the amount of drug administered over the study divided by the amount of drug that would have been received had the $150 \mathrm{mg}$ bid dose been administered throughout the 52-week study or until discontinuation in patients who discontinued prematurely. A pre-specified subgroup analysis assessed the impact of dose intensity ( $\leq 90 \%$ versus $>90 \%)$ on the annual rate of decline in $\mathrm{FVC}$ using pooled data from the two trials.

Compliance with study medication was defined as the number of capsules taken divided by the number of capsules that should have been taken over the trial period. Safety was assessed by means of clinical and laboratory evaluation, clinical assessment of vital signs and physical examination at study visits and the recording of adverse

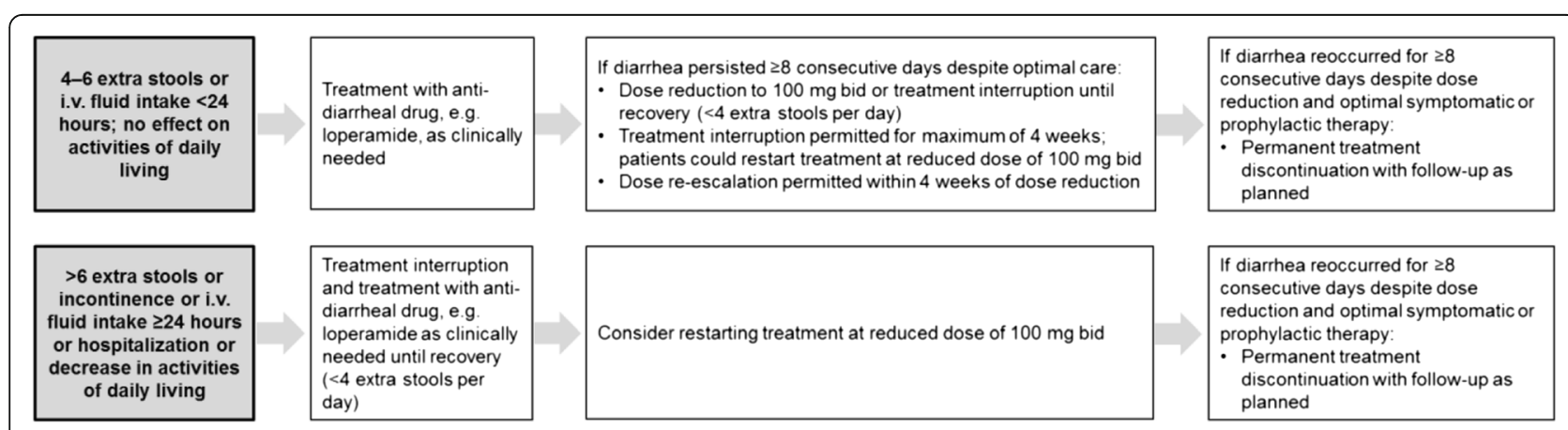

Fig. 1 Algorithm for the management of diarrhea adverse events in the INPULSIS ${ }^{\circledR}$ trials. i.V., intravenous 


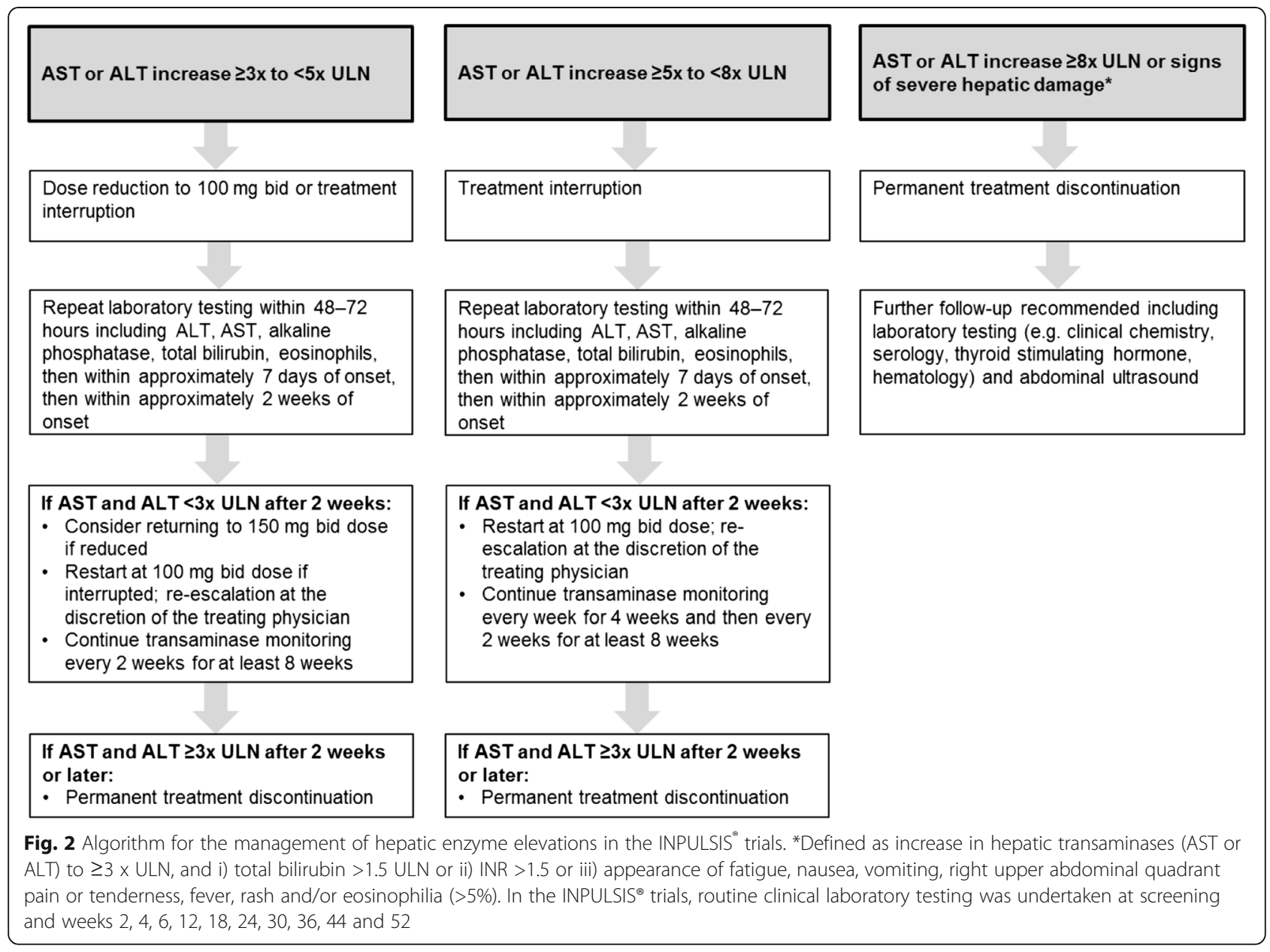

events, coded according to the Medical Dictionary for Regulatory Activities (MedDRA) version 16.1. The analyses were descriptive and based on patients who received $\geq 1$ dose of study medication. Patients with adverse events with onset after the first dose and up to 28 days after the last dose of trial medication were included in the analysis. The intensity of adverse events was rated by the investigators as mild (easily tolerated), moderate (enough discomfort to cause interference with usual activity) or severe (incapacitating or causing inability to work or to perform usual activities). For every adverse event, investigators reported whether they considered the event was related to study drug. For patients who experienced $\geq 1$ diarrhea adverse event, the duration of diarrhea adverse events was calculated as the total duration of all the events. A specific diarrhea electronic case report form (eCRF) was introduced during the course of the trials to characterize diarrhea adverse events. Routine clinical laboratory testing was undertaken at screening and weeks 2 , $4,6,12,18,24,30,36,44$ and 52.

Both trials were conducted in accordance with the principles of the Declaration of Helsinki and the Harmonised Tripartite Guideline for Good Clinical Practice from the International Conference on Harmonisation and were approved by local authorities. The clinical protocol was approved by an independent ethics committee or institutional review board at each participating center. All patients provided written informed consent before study entry.

\section{Results}

\section{Patients}

A total of 1061 patients were treated in the two INPULSIS $^{\circ}$ trials, 638 in the nintedanib group and 423 in the placebo group. Demographics and baseline characteristics were comparable between the treatment groups (Table 1 and Additional file 1).

\section{Exposure}

The mean (standard deviation [SD]) duration of exposure was 10.3 (3.4) months in the nintedanib group and 10.8 (2.8) months in the placebo group. Compliance with study medication was $96.4 \%$ in the nintedanib group and $96.7 \%$ in the placebo group.

A summary of the proportion of patients requiring dose reductions and treatment interruptions is presented 
Table 1 Baseline demographics and clinical characteristics in the INPULSIS ${ }^{\oplus}$ trials

\begin{tabular}{|c|c|c|}
\hline & $\begin{array}{l}\text { Nintedanib } \\
(n=638)\end{array}$ & $\begin{array}{l}\text { Placebo } \\
(n=423)\end{array}$ \\
\hline Male, n (\%) & $507(79.5)$ & $334(79.0)$ \\
\hline Age, years, mean (SD) & $66.6(8.1)$ & $67.0(7.9)$ \\
\hline Weight, kg, mean (SD) & $79.2(16.6)$ & $78.6(16.5)$ \\
\hline \multicolumn{3}{|l|}{ Race, n (\%) } \\
\hline White & $360(56.4)$ & $248(58.6)$ \\
\hline Asian & $194(30.4)$ & $128(30.3)$ \\
\hline Black & $2(0.3)$ & $0(0.0)$ \\
\hline Missing ${ }^{a}$ & $82(12.9)$ & $47(11.1)$ \\
\hline \multicolumn{3}{|l|}{ Smoking status, n (\%) } \\
\hline Never smoked & $174(27.3)$ & $122(28.8)$ \\
\hline Ex-smoker & $435(68.2)$ & $283(66.9)$ \\
\hline Current smoker & $29(4.5)$ & $18(4.3)$ \\
\hline Time since diagnosis of IPF, years, mean $(S D)^{b}$ & $1.7(1.4)$ & $1.6(1.3)$ \\
\hline FVC, mL, mean (SD) & $2714(757)$ & $2728(810)$ \\
\hline FVC, \% predicted, mean (SD) & $79.7(17.6)$ & $79.3(18.2)$ \\
\hline $\mathrm{FEV}_{1} / \mathrm{FVC}$ ratio, \%, mean (SD) & $81.7(5.8)$ & $81.7(6.0)$ \\
\hline $\mathrm{DL}_{\mathrm{CO}}, \%$ predicted, mean (SD) & $47.4(13.5)$ & $47.0(13.4)$ \\
\hline $\mathrm{SpO}_{2}, \%$, mean (SD) & $95.9(2.3)$ & $95.8(2.0)$ \\
\hline SGRQ total score, mean $(S D)^{c}$ & $39.5(19.2)$ & 39.6 (18.5) \\
\hline
\end{tabular}

Based on patients who received $\geq 1$ dose of study medication. Data collected at screening unless otherwise stated

alt was not permitted to collect data on race in France

${ }^{\mathrm{b}}$ At randomization

${ }^{c} n=624$ for nintedanib $150 \mathrm{mg}$ bid and $n=419$ for placebo

in Table 2. The proportion of patients who had $\geq 1$ dose reduction from $150 \mathrm{mg}$ bid to $100 \mathrm{mg}$ bid was higher in the nintedanib group than in the placebo group (178 patients [27.9\%] versus 16 patients [3.8 \%]); 15 patients $(2.4 \%)$ in the nintedanib group and none in the placebo group had $\geq 2$ dose reductions from $150 \mathrm{mg}$ bid to $100 \mathrm{mg}$ bid. There was no distinct temporal pattern associated with dose reductions. Forty patients $(6.3 \%)$ in the nintedanib group and 7 patients (1.7\%) in the placebo group had $\geq 1$ dose increase from $100 \mathrm{mg}$ bid to $150 \mathrm{mg}$ bid. In total, $76.3 \%$ of patients in the nintedanib group and $97.9 \%$ of patients in the placebo group received $150 \mathrm{mg}$ bid as their last dose.

A greater proportion of patients treated with nintedanib had $\geq 1$ treatment interruption than those treated with placebo ( $23.7 \%$ versus $9.9 \%$ ); 38 patients $(6.0 \%)$ in the nintedanib group and 3 patients $(0.7 \%)$ in the placebo group had $\geq 2$ treatment interruptions. There was no discernible accumulation of dose interruptions during a specific time period during the trials. The mean (SD) duration of interruption was 25.1 (18.8) and 25.6 (15.3) days in the nintedanib and placebo groups, respectively.
Table 2 Dose reductions and treatment interruptions in the INPULSIS ${ }^{\circ}$ trials

\begin{tabular}{|c|c|c|}
\hline N (\%) & $\begin{array}{l}\text { Nintedanib } \\
(n=638)\end{array}$ & $\begin{array}{l}\text { Placebo } \\
(n=423)\end{array}$ \\
\hline \multicolumn{3}{|l|}{ Dose reductions } \\
\hline Patients with $\geq 1$ dose reduction & $178(27.9)$ & $16(3.8)$ \\
\hline \multicolumn{3}{|l|}{ Dose reductions per patient } \\
\hline 1 & $163(25.5)$ & $16(3.8)$ \\
\hline 2 & $13(2.0)$ & $0(0.0)$ \\
\hline$>2$ & $2(0.3)$ & $0(0.0)$ \\
\hline \multicolumn{3}{|l|}{ Time to first dose reduction } \\
\hline$\leq 1$ month & $20(3.1)$ & $1(0.2)$ \\
\hline$>1$ month to $\leq 2$ months & $28(4.4)$ & $4(0.9)$ \\
\hline$>2$ month to $\leq 3$ months & $19(3.0)$ & $0(0.0)$ \\
\hline$>3$ month to $\leq 4$ months & $18(2.8)$ & $3(0.7)$ \\
\hline$>4$ month to $\leq 5$ months & $24(3.8)$ & $1(0.2)$ \\
\hline$>5$ month to $\leq 6$ months & $22(3.4)$ & $1(0.2)$ \\
\hline$>6$ months & $47(7.4)$ & $6(1.4)$ \\
\hline $\begin{array}{l}\text { Patients with } \geq 1 \text { dose increase to } \\
150 \mathrm{mg} \text { bid }\end{array}$ & $40(6.3)$ & $7(1.7)$ \\
\hline $\begin{array}{l}\text { Patients who took } 150 \mathrm{mg} \text { bid } \\
\text { as last dose }\end{array}$ & $487(76.3)$ & $414(97.9)$ \\
\hline Treatment interruptions & & \\
\hline
\end{tabular}

\section{interruption}

Treatment interruptions per patient

1
2
$>2$

$\begin{array}{ll}113(17.7) & 39(9.2) \\ 30(4.7) & 3(0.7) \\ 8(1.3) & 0(0.0)\end{array}$

Time to first treatment interruption

$$
\begin{aligned}
& \leq 1 \text { month } \\
& >1 \text { month to } \leq 2 \text { months } \\
& >2 \text { month to } \leq 3 \text { months } \\
& >3 \text { month to } \leq 4 \text { months } \\
& >4 \text { month to } \leq 5 \text { months } \\
& >5 \text { month to } \leq 6 \text { months } \\
& >6 \text { months }
\end{aligned}
$$

\begin{tabular}{ll}
$32(5.0)$ & $3(0.7)$ \\
$18(2.8)$ & $4(0.9)$ \\
$18(2.8)$ & $6(1.4)$ \\
$21(3.3)$ & $4(0.9)$ \\
$18(2.8)$ & $2(0.5)$ \\
$11(1.7)$ & $3(0.7)$ \\
$33(5.2)$ & $20(4.7)$ \\
$20(13.2)$ & $1(2.4)$ \\
$81(53.6)$ & $9(21.4)$ \\
$49(32.5)$ & $32(76.2)$ \\
$1(0.7)$ & \\
\hline
\end{tabular}

Patients re-introduced at the same dose of $100 \mathrm{mg}$ bid after treatment interruption $^{a}$

Patients re-introduced at a reduced dose of $100 \mathrm{mg}$ bid after treatment interruption $^{\mathrm{a}}$

Patients re-introduced at the same dose of $150 \mathrm{mg}$ bid after treatment interruption $^{\mathrm{a}}$

Patients re-introduced at an increased dose of $150 \mathrm{mg}$ bid after treatment interruption $^{a}$

Based on patients who received $\geq 1$ dose of study medication ${ }^{a}$ Dose at last re-introduction 
In total, $24.5 \%$ of patients in the nintedanib group and $18.9 \%$ in the placebo group prematurely discontinued trial medication; $19.3 \%$ and $13.0 \%$ of patients treated with nintedanib and placebo, respectively, prematurely discontinued trial medication due to an adverse event.

Mean dose intensity was high in both treatment groups. In the subgroup of patients with dose intensity $>90 \%$ $(n=484)$, mean (SD) dose intensity was $99.3(2.2) \%$ in patients treated with nintedanib and 99.8 (1.6) \% in patients treated with placebo. In the subgroup of patients with dose intensity $\leq 90 \%(n=154)$, mean (SD) dose intensity was $76.1(10.1) \%$ in patients treated with nintedanib and 80.5 (7.5) \% in patients treated with placebo. The adjusted annual rate of decline in FVC was of similar magnitude in patients treated with nintedanib with dose intensity $>90 \%$ as in patients treated with nintedanib with dose intensity $\leq 90 \%$ (mean [standard error] 112.7 [12.8] and 72.7 [24.3] $\mathrm{ml} /$ year, respectively).

\section{Adverse events}

A summary of adverse events is presented in Table 3. In total, $95.5 \%$ of patients treated with nintedanib and $89.6 \%$ of patients treated with placebo experienced $\geq 1$ adverse event. The proportion of patients who had $\geq 1$ serious adverse event was similar between the nintedanib (30.4\%) and placebo (30.0 \%) groups.

Diarrhea was the most frequently reported adverse event in the nintedanib group, reported in $62.4 \%$ of patients compared with $18.4 \%$ of patients in the placebo group. A summary of diarrhea adverse events and their clinical consequences is presented in Table 4. Almost all patients who reported diarrhea adverse events (nintedanib: $94.5 \%$, placebo: $97.4 \%$ ) reported events of mild or moderate intensity. Of patients who had $\geq 1$ completed eCRF specific for diarrhea $(n=185$ in the nintedanib group; $n=25$ in the placebo group), most had $<4$ extra stools per day (nintedanib: 111 patients [60.0\%], placebo: 19 patients [76.0 \%]). Bowel movements were most commonly characterized as watery with or without formed stool. Among patients who experienced a diarrhea adverse event, anti-diarrheal therapies (most commonly loperamide) were used by $55.3 \%$ of patients in the nintedanib group and $25.6 \%$ of patients in the placebo group during the on-treatment period. For most patients who reported diarrhea adverse events (nintedanib: $78.6 \%$, placebo: $98.7 \%$ ), the events resolved without the need for dose reduction or treatment interruption. A small proportion of patients had a permanent dose reduction (nintedanib: 68 patients [10.7 \%], placebo: no patients) and/or discontinued trial medication prematurely due to diarrhea (nintedanib: 28 patients [4.4 \%], placebo: 1 [0.2\%]). Among patients who experienced any diarrhea adverse events, most reported a single
Table 3 Patients with adverse events in the INPULSIS ${ }^{\circ}$ trials

\begin{tabular}{lll}
\hline N (\%) & $\begin{array}{l}\text { Nintedanib } \\
(n=638)\end{array}$ & $\begin{array}{l}\text { Placebo } \\
(n=423)\end{array}$ \\
\hline $\begin{array}{l}\text { Any adverse event(s) } \\
\text { Most frequent adverse events }{ }^{\mathrm{a}}\end{array}$ & $609(95.5)$ & $379(89.6)$ \\
Diarrhea & $398(62.4)$ & $78(18.4)$ \\
Nausea & $156(24.5)$ & $28(6.6)$ \\
Nasopharyngitis & $87(13.6)$ & $68(16.1)$ \\
Cough & $85(13.3)$ & $57(13.5)$ \\
$\begin{array}{l}\text { Progression of idiopathic } \\
\text { pulmonary fibrosis }\end{array}$ & $64(10.0)$ & $61(14.4)$ \\
Bronchitis & $67(10.5)$ & $45(10.6)$ \\
Dyspnea & $49(7.7)$ & $48(11.3)$ \\
Decreased appetite & $68(10.7)$ & $24(5.7)$ \\
Vomiting & $74(11.6)$ & $11(2.6)$ \\
Adverse event(s) leading to \\
permanent dose reduction \\
Adverse event(s) leading to & $101(15.8)$ & $2(0.5)$ \\
\hline
\end{tabular}

permanent treatment discontinuation

Adverse events that most frequently

led to permanent treatment

discontinuation $^{c}$

\begin{tabular}{|c|c|c|}
\hline $\begin{array}{l}\text { Progression of idiopathic pulmonary } \\
\text { fibrosis }^{\mathrm{b}}\end{array}$ & $13(2.0)$ & $21(5.0)$ \\
\hline Diarrhea & $28(4.4)$ & $1(0.2)$ \\
\hline Nausea & $13(2.0)$ & $0(0.0)$ \\
\hline Decreased appetite & $9(1.4)$ & $1(0.2)$ \\
\hline Pneumonia & $6(0.9)$ & $1(0.2)$ \\
\hline Weight decreased & $6(0.9)$ & $1(0.2)$ \\
\hline Abdominal pain & $5(0.8)$ & $1(0.2)$ \\
\hline Vomiting & $5(0.8)$ & $0(0.0)$ \\
\hline Asthenia & $4(0.6)$ & $0(0.0)$ \\
\hline Increased alanine aminotransferase & $4(0.6)$ & $0(0.0)$ \\
\hline $\begin{array}{l}\text { rug-related adverse events (as reported } \\
y \text { the investigators) }\end{array}$ & $455(71.3)$ & $120(28.4)$ \\
\hline evere adverse events ${ }^{d}$ & $174(27.3)$ & $99(23.4)$ \\
\hline erious adverse events ${ }^{\mathrm{e}}$ & $194(30.4)$ & $127(30.0)$ \\
\hline atal adverse event(s) & $37(5.8)$ & $31(7.3)$ \\
\hline
\end{tabular}

Based on patients who received $\geq 1$ dose of study medication

${ }^{a}$ Adverse events reported in $>10 \%$ of patients in either treatment group

${ }^{b}$ Corresponds to the MedDRA term 'IPF', which included disease worsening and IPF exacerbations

${ }^{c}$ Adverse events leading to permanent treatment discontinuation in $>0.5 \%$ of patients in either treatment group, by preferred term

${ }^{\mathrm{d}} \mathrm{A}$ severe adverse event was related to intensity and was defined as an event that was incapacitating or that caused an inability to work or to perform usual activities

${ }^{\mathrm{e}} \mathrm{A}$ serious adverse event was defined as any adverse event that resulted in death, was immediately life-threatening, resulted in persistent or clinically significant disability or incapacity, required or prolonged hospitalization, was related to a congenital anomaly or birth defect or was deemed serious for any other reason 
Table 4 Gastrointestinal adverse events and clinical consequences in the INPULSIS ${ }^{\circ}$ trials

\begin{tabular}{|c|c|c|c|c|c|c|}
\hline & \multicolumn{2}{|l|}{ Diarrhea } & \multicolumn{2}{|l|}{ Nausea } & \multicolumn{2}{|l|}{ Vomiting } \\
\hline & Nintedanib & Placebo & Nintedanib & Placebo & Nintedanib & Placebo \\
\hline & $(n=398)$ & $(n=78)$ & $(n=156)$ & $(n=28)$ & $(n=74)$ & $(n=11)$ \\
\hline \multicolumn{7}{|l|}{ Intensity of adverse event ${ }^{a}$} \\
\hline Mild & $226(56.8)$ & $60(76.9)$ & $116(74.4)$ & $26(92.9)$ & $49(66.2)$ & $9(81.8)$ \\
\hline Moderate & $150(37.7)$ & $16(20.5)$ & $38(24.4)$ & $2(7.1)$ & $21(28.4)$ & $2(18.2)$ \\
\hline Severe & $21(5.3)$ & $2(2.6)$ & $2(1.3)$ & $0(0.0)$ & $4(5.4)$ & $0(0.0)$ \\
\hline \multicolumn{7}{|l|}{ Outcome of adverse event ${ }^{a}$} \\
\hline Recovered & $350(87.9)$ & $72(92.3)$ & $143(91.7)$ & $22(78.6)$ & 69 (93.2) & $11(100.0)$ \\
\hline Not yet recovered ${ }^{b}$ & $43(10.8)$ & $6(7.7)$ & $12(7.7)$ & $6(21.4)$ & $5(6.8)$ & $0(0.0)$ \\
\hline Fatal & $0(0.0)$ & $0(0.0)$ & $0(0.0)$ & $0(0.0)$ & $0(0.0)$ & $0(0.0)$ \\
\hline Unknown & $5(1.3)$ & $0(0.0)$ & $1(0.6)$ & $0(0.0)$ & $0(0.0)$ & $0(0.0)$ \\
\hline \multicolumn{7}{|l|}{ Consequence for dosing ${ }^{c}$} \\
\hline No permanent dose reduction or discontinuation ${ }^{d}$ & $313(78.6)$ & $77(98.7)$ & $135(86.5)$ & $28(100.0)$ & $64(86.5)$ & $11(100.0)$ \\
\hline Permanent dose reduction of trial drug & $57(14.3)$ & $0(0.0)$ & $8(5.1)$ & $0(0.0)$ & $5(6.8)$ & $0(0.0)$ \\
\hline Permanent discontinuation of trial drug & $28(7.0)$ & $1(1.3)$ & $13(8.3)$ & $0(0.0)$ & $5(6.8)$ & $0(0.0)$ \\
\hline \multicolumn{7}{|l|}{ Number of adverse events } \\
\hline 1 & $240(60.3)$ & $60(76.9)$ & $116(74.4)$ & $27(96.4)$ & $54(73.0)$ & $11(100.0)$ \\
\hline 2 & $105(26.4)$ & $12(15.4)$ & $31(19.9)$ & $1(3.6)$ & $14(18.9)$ & $0(0.0)$ \\
\hline 3 & $29(7.3)$ & $3(3.8)$ & $8(5.1)$ & $0(0.0)$ & $4(5.4)$ & $0(0.0)$ \\
\hline$\geq 4$ & $24(6.0)$ & $3(3.8)$ & $1(0.6)$ & $0(0.0)$ & $2(2.7)$ & $0(0.0)$ \\
\hline Duration of events, days, median (minimum, maximum) ${ }^{\mathrm{e}}$ & $138.5(1,473)$ & $7.0(1,453)$ & $44.0(1,400)$ & $51.0(1,404)$ & $6.0(1,390)$ & $1.0(1,4)$ \\
\hline
\end{tabular}

Data are $\mathrm{N}(\%)$ of patients with $\geq 1$ diarrhea or nausea or vomiting adverse events unless otherwise stated

${ }^{a}$ For patients with more with one event, the intensity/outcome of the worst event is displayed

${ }^{\mathrm{b}}$ The patient has not yet returned to his/her previous health status, continues to be followed for the adverse event, but is expected to recover without sequelae ${ }^{\mathrm{C}}$ For patients with more than one event, the last consequence for dosing is displayed

dincludes patients with temporary dose reductions or treatment interruptions

${ }^{\mathrm{e}}$ For patients who experienced $\geq 1$ adverse event, the duration of adverse events was calculated as the total duration of all the events; the definition of a single event was not specified to the investigators in the trial protocol

event (nintedanib: $60.3 \%$; placebo: $76.9 \%$ ) or 2 events (nintedanib: $26.4 \%$; placebo: $15.4 \%$ ). The median (minimum, maximum) duration of diarrhea events was 138.5 $(1,473)$ days in the nintedanib group and $7.0(1,453)$ days in the placebo group. For most patients with a diarrhea adverse event, the first onset occurred within the first 3 months of treatment (Fig. 3).

In a post-hoc analysis, the absolute mean (SD) change from baseline in FVC at week 52 was $-67.7(271.4) \mathrm{ml}$ for nintedanib-treated patients who experienced $\geq 1$ diarrhea adverse event $(n=398)$ and $-129.4(246.0) \mathrm{ml}$ for nintedanib-treated patients without any diarrhea events $(n=240)$. For patients treated with placebo, the absolute mean (SD) change from baseline in FVC at week 52 was $-227.7(283.6) \mathrm{ml}$ for patients who experienced $\geq 1$ diarrhea adverse event $(n=78)$ and $-197.3(294.7) \mathrm{ml}$ for patients without any diarrhea events $(n=345)$.

A summary of nausea and vomiting adverse events is presented in Table 4. Almost all nausea and vomiting adverse events were mild or moderate in intensity. Most patients who experienced nausea reported only 1 event (nintedanib: $74.4 \%$; placebo: $96.4 \%$ ). Similarly, most patients who experienced vomiting reported only 1 event (nintedanib: 54 patients [73.0 \%], placebo: 11 patients [100\%]). The majority of nausea adverse events had an early onset; vomiting adverse events occurred at any time relative to the start of treatment.

A summary of the proportions of patients with elevations in hepatic enzymes is shown in Table 5. For ALT, AST and bilirubin, the proportion of patients who had normal values at baseline but maximum values above the ULN during treatment was higher in the nintedanib group than in the placebo group. In the majority of patients, values had returned to values within the normal range by the end of treatment. Nevertheless, a greater proportion of patients in the nintedanib group than in the placebo group had a last value on treatment above the ULN for ALT (4.4\% versus $3.4 \%$ ) and AST (5.0 \% versus $1.7 \%$ ). While it is difficult to identify a pattern due to the low number of patients with ALT and/or AST elevations $\geq 3 \mathrm{x}$ ULN, the elevations 


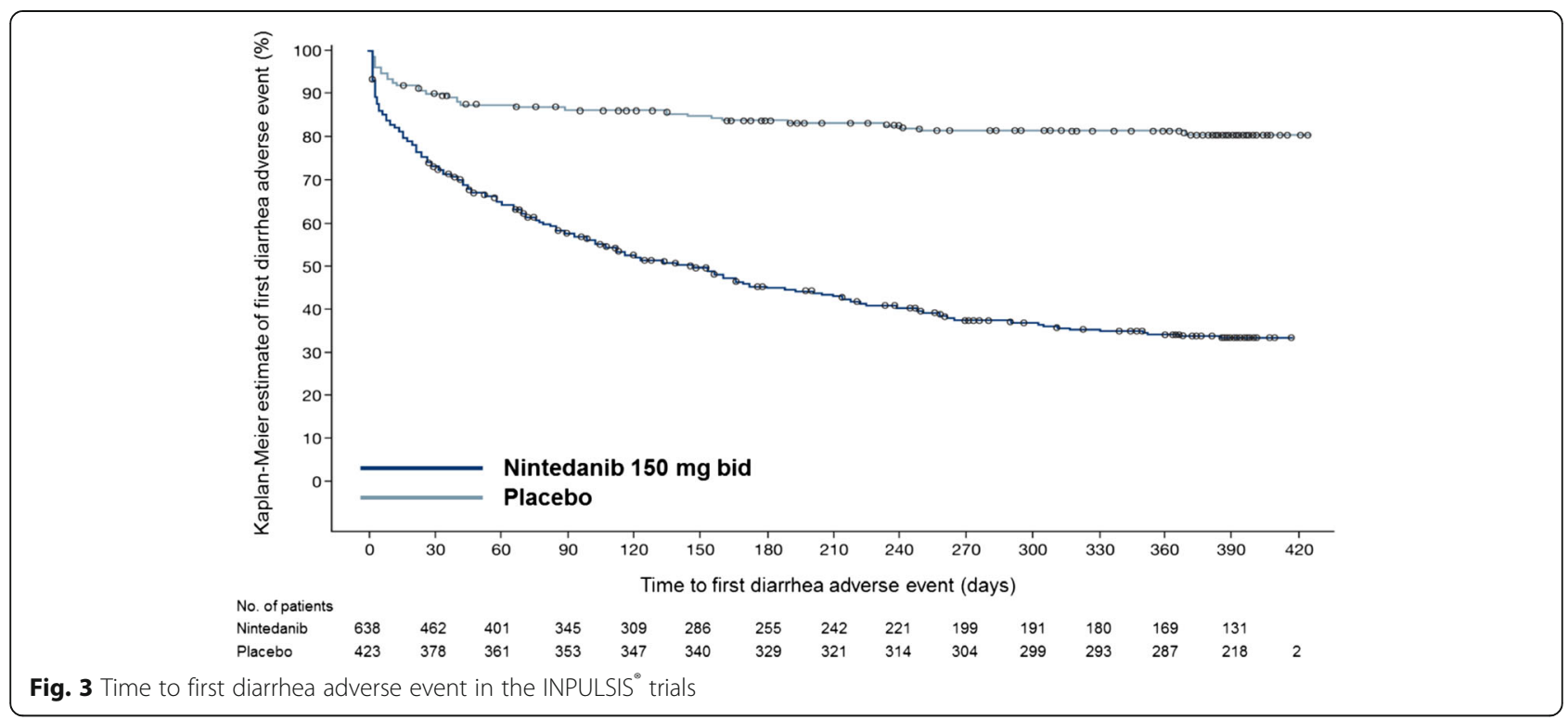

Table 5 Hepatic enzyme elevation adverse events in the INPULSIS ${ }^{\circ}$ trials

\begin{tabular}{|c|c|c|}
\hline N (\%) & $\begin{array}{l}\text { Nintedanib } \\
(n=638)\end{array}$ & $\begin{array}{l}\text { Placebo } \\
(n=423)\end{array}$ \\
\hline \multicolumn{3}{|l|}{ Elevations in ALT and/or AST } \\
\hline$\geq 3 \times$ ULN & $32(5.0)$ & $3(0.7)$ \\
\hline$\geq 5 x$ ULN & $14(2.2)$ & $1(0.2)$ \\
\hline$\geq 8 \times$ ULN & $5(0.8)$ & $1(0.2)$ \\
\hline \multicolumn{3}{|l|}{ Elevations in maximum total bilirubin } \\
\hline$\geq 1.5 \times$ ULN & $15(2.4)$ & $3(0.7)$ \\
\hline$\geq 2 \times U L N$ & $3(0.5)$ & $2(0.5)$ \\
\hline \multicolumn{3}{|l|}{ Elevations in maximum alkaline phosphatase } \\
\hline$\geq 1.5 \times$ ULN & $37(5.8)$ & $4(0.9)$ \\
\hline$\geq 2 \times$ ULN & $17(2.7)$ & $1(0.2)$ \\
\hline $\begin{array}{l}\text { Normal ALT values at baseline but maximum } \\
\text { value on treatment }>\text { ULN on treatment }{ }^{\mathrm{a}}\end{array}$ & $169(27.3)$ & $30(7.2)$ \\
\hline $\begin{array}{l}\text { Normal AST values at baseline but maximum } \\
\text { value on treatment }>U L N^{b}\end{array}$ & $134(21.4)$ & $22(5.3)$ \\
\hline $\begin{array}{l}\text { Normal bilirubin values at baseline but maximum } \\
\text { value on treatment }>U L N^{c}\end{array}$ & $48(7.7)$ & $22(5.3)$ \\
\hline $\begin{array}{l}\text { Normal alkaline phosphatase values at baseline } \\
\text { but maximum value on treatment }>U \operatorname{UN}^{d}\end{array}$ & $94(15.3)$ & $28(6.8)$ \\
\hline
\end{tabular}

Based on patients who received $\geq 1$ dose of study medication. Categories are cumulative

anintedanib $n=620$, placebo $n=416 ;{ }^{b}$ nintedanib $n=625$, placebo $n=418$; cnintedanib $n=621$, placebo $n=413$; ${ }^{d}$ nintedanib $n=615$, placebo $n=412$ Hy's law criteria were met in no patients in the nintedanib group and in 1 patient in the placebo group. Hy's law criteria: AST or ALT $\geq 3 x$ ULN and total bilirubin $\geq 2 x$ ULN measured in the same blood sample, and no other reason found to explain the combination of increased hepatic transaminases and bilirubin, such as viral hepatitis A, B or C; pre-existing or acute hepatic disease; or the use of another drug capable of causing the observed injury appeared not to occur at a particular time relative to the start of treatment. Thirty-two patients $(5.0 \%)$ in the nintedanib group and 3 patients $(0.7 \%)$ in the placebo group had ALT and/or AST elevations $\geq 3 x$ ULN. Hy's law criteria were met in 1 patient (in the placebo group).

With regards to other adverse events of interest, bleeding events were reported in $10.3 \%$ of patients in the nintedanib group and $7.8 \%$ of patients in the placebo group. Epistaxis, which occurred in 26 patients (4.1\%) in the nintedanib group and $13(3.1 \%)$ in the placebo group and contusion, which occurred in 10 patients $(1.6 \%)$ in the nintedanib group and $4(0.9 \%)$ in the placebo group, were the most frequently reported bleeding events. Serious bleeding events occurred with similar incidences in both treatment groups (8 patients [1.3 \%] in the nintedanib group and 6 [1.4\%] in the placebo group. Gastrointestinal perforation was reported in 2 patients $(0.3 \%)$ in the nintedanib group and no patients in the placebo group. Hypertension was reported in 33 patients (5.2\%) in the nintedanib group and $17(4.0 \%)$ in the placebo group.

Cardiac disorder adverse events were reported in $10.0 \%$ of patients treated with nintedanib and $10.6 \%$ of patients treated with placebo (Additional file 2). Serious cardiac disorder adverse events were reported in $5.0 \%$ of patients in the nintedanib group and $5.4 \%$ of patients in the placebo group; fatal cardiac disorders occurred in 3 patients $(0.5 \%)$ and 6 patients $(1.4 \%)$ in the nintedanib and placebo groups, respectively. The MedDRA category of 'ischemic heart disease' was reported in a similar proportion of patients in the nintedanib (4.2\%) and placebo (4.0\%) groups (Additional file 2). Within the MedDRA category of 'ischemic heart disease', a higher proportion of patients reported an event in the 
subcategory 'myocardial infarction' in the nintedanib group (17 patients [2.7\%]) compared with the placebo group (5 patients [1.2 \%]), but a lower proportion of patients reported an event in the other subcategory, 'other ischemic heart disease', in the nintedanib group (11 patients $[1.7 \%]$ ) than in the placebo group (13 patients ([3.1 \%]) (Additional file 2). The MedDRA preferred terms of myocardial infarction or acute myocardial infarction were reported in 10 patients $(1.6 \%)$ treated with nintedanib and 2 patients $(0.5 \%)$ treated with placebo.

A higher proportion of patients experienced weight loss as an adverse event in the nintedanib group (9.7\%) than in the placebo group (3.5\%). The mean change from baseline in body weight at week 52 was $-3.1 \mathrm{~kg}$ in the nintedanib group and $-1.4 \mathrm{~kg}$ in the placebo group. The proportion of patients with infection adverse events was similar in both treatment groups (nintedanib: $56.3 \%$; placebo: $53.9 \%$ ) as was the proportion of patients with adverse events related to respiratory, thoracic and mediastinal disorders (nintedanib: $39.8 \%$; placebo: $41.8 \%)$.

\section{Discussion}

We report collective safety data for nintedanib from the two Phase III INPULSIS trials. These data demonstrate that nintedanib has a manageable safety and tolerability profile in patients with IPF.

In the INPULSIS trials, the investigators were provided with recommendations for the management of adverse events, including symptomatic measures as well as the option of a flexible dosing regimen. These recommendations provide guidance for the management of adverse events associated with the use of nintedanib in clinical practice. Although a greater proportion of patients in the nintedanib group had a dose reduction or treatment interruption compared with patients in the placebo group, mean dose intensity in the nintedanib group was high. A pre-specified subgroup analysis demonstrated that nintedanib reduced FVC decline both in patients with a dose intensity of $\leq 90 \%$ and in patients with a dose intensity $>90 \%$, suggesting that dose reductions or treatment interruptions made to manage adverse events had no major impact on the efficacy of nintedanib.

As expected based on data from previous studies in patients with IPF [10] and patients with solid tumors $[13,14]$, the most frequently reported adverse events in patients treated with nintedanib in the INPULSIS ${ }^{\circ}$ trials were gastrointestinal in nature, particularly diarrhea, nausea, vomiting and decreased appetite. Almost all such adverse events were mild or moderate in intensity and most resolved without the need for dose reduction or treatment interruption. A limitation of our studies was that the definition of a single diarrhea event was not specified to the investigators in the trial protocol. Thus, for patients with intermittent diarrhea over a prolonged period, some investigators may have reported this as several events and others as a single event, reducing the precision of our estimate of the number and the duration of diarrhea events. Only $4.4 \%$ of patients in the nintedanib group discontinued trial medication prematurely due to diarrhea, suggesting that recommendations for the management of diarrhea, including symptomatic treatment with anti-diarrheal therapies, were successful in minimizing permanent treatment discontinuations. However, only $55.3 \%$ of patients treated with nintedanib who experienced a diarrhea adverse event received symptomatic anti-diarrheal treatment during the ontreatment period, indicating that there is a need to provide adequate information to physicians in clinical practice and patients about the early management of diarrhea to enable patients to continue taking the drug and so receive maximum benefit from nintedanib treatment. This also applies to anti-emetic treatments. It is recommended that patients treated with nintedanib who experience diarrhea should maintain hydration and take antidiarrheal therapy (e.g., loperamide) as soon as symptoms occur. Dose reduction from $150 \mathrm{mg}$ bid to $100 \mathrm{mg}$ bid or temporary treatment interruption can also be considered. If diarrhea persists, nintedanib should be discontinued. The exact mechanism by which tyrosine kinase inhibition causes nausea or diarrhea is unknown; however, VEGF and VEGF receptors (VEGFR) are known to be highly expressed in the endocrine glands, stomach and intestines, suggesting that VEGF inhibition may cause morphometric changes in the bowel mucosa $[15,16]$. A post-hoc analysis of data from the INPULSIS ${ }^{\circ}$ trials showed that nintedanib was effective both in patients who had $\geq 1$ diarrhea adverse event and patients who had no diarrhea adverse events, with a lower mean decline in FVC in patients who had $\geq 1$ diarrhea adverse event. Although the limitations of this descriptive analysis do not allow firm conclusions to be drawn regarding the lower mean decline in FVC in patients who had diarrhea, trials investigating the use of tyrosine kinase inhibitors in oncology have reported an association between drug-related adverse events such as rash and diarrhea and efficacy $[17,18]$.

In addition to diarrhea, adverse events associated with inhibition of VEGF or VEGFR include arterial hypertension, gastrointestinal perforations, thromboembolism and bleeding $[19,20]$ and therefore these are potential risks of nintedanib treatment. Patients treated with fulldose anticoagulation or at known risk for bleeding were excluded from the INPULSIS ${ }^{\circ}$ studies. This has led to recommendations stating that patients at known risk for bleeding should be treated with nintedanib only if the anticipated benefit outweighs the potential risk. 
The mechanism behind the elevations in hepatic enzymes or bilirubin following treatment with nintedanib is not well understood, but requires laboratory testing before and periodically during treatment (e.g., during regular patient visits). In general, elevations in hepatic enzymes and total bilirubin were uncommon and returned to normal following dose reduction or treatment interruption.

Although cardiac disorders adverse events were balanced between the nintedanib and placebo groups, a higher proportion of patients in the nintedanib groups had myocardial infarctions. Conversely, a lower proportion of patients in the nintedanib groups had other ischemic heart disease. The clinical significance of this finding is unknown, and further observation is needed. However, it should be noted that the prevalence of myocardial infarctions in the INPULSIS trials was low and below that observed in patients with IPF based on data from two US health claims databases [21].

In conclusion, pooled safety data from the INPULSIS trials demonstrate that the dosing regimen utilized and the recommendations given for the management of adverse events, including symptomatic measures and hepatic enzyme monitoring, were successful in minimizing permanent treatment discontinuations. Nintedanib had a manageable safety and tolerability profile in patients with IPF. Physicians, nurses and patients will benefit from clear instructions on how to monitor patients and manage adverse events that may be associated with treatment with nintedanib, consistent with those implemented in the INPULSIS trials.

\section{Additional files}

\section{Additional file 1: Baseline conditions and therapies in the}

INPULSIS trials. (DOCX $15 \mathrm{~kb}$ )

Additional file 2: Cardiac disorders and ischaemic heart disease in the INPULSIS trials. (DOCX $14 \mathrm{~kb}$ )

\section{Competing interests}

The INPULSIS ${ }^{\circ}$ trials were funded by Boehringer Ingelheim. CC, KP and MQ are employees of Boehringer Ingelheim. TC has received fees for consulting and serving on advisory boards for Boehringer Ingelheim and AstraZeneca; for contributing to educational materials for Boehringer Ingelheim and Actelion; travel support from Actelion, GlaxoSmithKline and Boehringer Ingelheim, and has received unrestricted educational grants from Actelion, Boehringer Ingelheim and InterMune. FB reports receipt of travel grants and speaker honoraria from Boehringer Ingelheim, as well as serving on advisory boards. BC reports receipt of grants, personal fees and non-financial support from InterMune and Boehringer Ingelheim; personal fees and non-financial support from Sanofi; grants from Cardif and Medlmmune, and personal fees from AstraZeneca. MGD reports receipt of personal fees from Boehringer Ingelheim for being a member of the Data Monitoring Committee for the INPULSIS trials. LR reports receipt of grants and personal fees from Boehringer Ingelheim for being a member of the INPULSIS ${ }^{\circ}$ steering committee and co-principal investigator of the trials; grants and personal fees from InterMune for being a member of an advisory board; personal fees from Medlmmune (advisory board member), Biogen-Idec (consulting), Sanofi-Aventis (consulting), Roche (advisory board member), Takeda (advisory board member),
ImmuneWorks (consulting), Shionogi (speaker honoraria) and GlaxoSmithKline (advisory board member). JAL reports compensation from Boehringer Ingelheim for participation in a Data Monitoring Committee and advisory committee, as well as educational speaker programs.

\section{Authors' contributions}

TC, BC and LR were investigators in the INPULSIS trials. LR contributed to the design of the INPULSIS ${ }^{\circ}$ trials through participation in the Steering Committee. MGD and JAL were co-chairs of the Data Monitoring Committee for the INPULSIS ${ }^{\circ}$ trials. All authors contributed to the interpretation of data and the development of this manuscript and have approved the final version.

\section{Acknowledgments}

Editorial assistance, supported financially by Boehringer Ingelheim, was provided by Julie Fleming and Wendy Morris of Fleishman-Hillard Group, Ltd, London, UK, during the preparation of this article. The authors were fully responsible for all content and editorial decisions, and were involved at all stages of manuscript development and have approved the final version.

\section{Author details}

${ }^{1}$ Royal Prince Alfred Hospital, Camperdown, New South Wales, Australia. ${ }^{2}$ University of Sydney, Sydney, New South Wales, Australia. ${ }^{3}$ Ruhrlandklinik, University Hospital, University of Duisburg-Essen, Essen, Germany. ${ }^{4}$ Hôpital Bichat, Pneumologie, Paris, France. ${ }^{5}$ University Hospital Leuven, Leuven, Belgium. ${ }^{6}$ National Institute for Health Research Southampton Respiratory Biomedical Research Unit and Clinical and Experimental Sciences, University of Southampton, Southampton, UK. ${ }^{7}$ SCS Boehringer Ingelheim Comm.V., Brussels, Belgium. ${ }^{8}$ Boehringer Ingelheim Ltd., Bracknell, UK. ${ }^{9}$ Boehringer Ingelheim Pharma GmbH \& Co. KG, Ingelheim am Rhein, Germany. ${ }^{10}$ Tulane University School of Medicine, New Orleans, LA, USA.

Received: 20 April 2015 Accepted: 14 September 2015

Published online: 24 September 2015

\section{References}

1. Fell CD, Martinez FJ, Liu LX, Murray S, Han MK, Kazerooni EA, et al. Clinical predictors of a diagnosis of idiopathic pulmonary fibrosis. Am J Respir Crit Care Med. 2010;181:832-7.

2. Nalysnyk L, Cid-Ruzafa J, Rotella P, Esser D. Incidence and prevalence of idiopathic pulmonary fibrosis: review of the literature. Eur Respir Rev. 2012;21:355-61.

3. Raghu G, Collard HR, Egan JJ, Martinez FJ, Behr J, Brown KK, et al. An official ATS/ERS/JRS/ALAT statement: idiopathic pulmonary fibrosis: evidence-based guidelines for diagnosis and management. Am J Respir Crit Care Med. 2011;183:788-824.

4. Swigris JJ, Stewart AL, Gould MK, Wilson SR. Patients' perspectives on how idiopathic pulmonary fibrosis affects the quality of their lives. Health Qual Life Outcomes. 2005;3:61.

5. Selman M, King TE, Pardo A, American Thoracic Society, European Respiratory Society, American College of Chest Physicians. Idiopathic pulmonary fibrosis: prevailing and evolving hypotheses about its pathogenesis and implications for therapy. Ann Intern Med. 2001;134:136-51.

6. Grimminger F, Schermuly RT, Ghofrani HA. Targeting non-malignant disorders with tyrosine kinase inhibitors. Nat Rev Drug Discov. 2010;9:956-70.

7. Ahluwalia N, Shea BS, Tager AM. New therapeutic targets in idiopathic pulmonary fibrosis: aiming to rein in runaway wound healing responses. Am J Respir Crit Care Med. 2014;190:867-78.

8. Hilberg F, Roth GJ, Krssak M, Kautschitsch S, Sommergruber W, TontschGrunt U, et al. BIBF 1120: triple angiokinase inhibitor with sustained receptor blockade and good antitumor efficacy. Cancer Res. 2008;68:4774-82.

9. Wollin L, Maillet I, Quesniaux V, Holweg A, Ryffel B. Antifibrotic and antiinflammatory activity of the tyrosine kinase inhibitor nintedanib in experimental models of lung fibrosis. J Pharmacol Exp Ther. 2014;349:209-20.

10. Richeldi L, Costabel U, Selman M, Kim DS, Hansell DM, Nicholson AG, et al. Efficacy of a tyrosine kinase inhibitor in idiopathic pulmonary fibrosis. $\mathrm{N}$ Engl J Med. 2011;365:1079-87.

11. Richeldi L, du Bois RM, Raghu G, Azuma A, Brown KK, Costabel U, et al. Efficacy and safety of nintedanib in idiopathic pulmonary fibrosis. N Engl J Med. 2014;370:2071-82. 
12. Richeldi L, Cottin V, Flaherty KR, Kolb M, Inoue Y, Raghu G, et al. Design of the INPULSIS ${ }^{\text {TM }}$ trials: Two phase 3 trials of nintedanib in patients with idiopathic pulmonary fibrosis. Respir Med. 2014;108:1023-30.

13. Reck M, Kaiser R, Eschbach C, Stefanic M, Love J, Gatzemeier U, et al. A phase II double-blind study to investigate efficacy and safety of two doses of the triple angiokinase inhibitor BIBF 1120 in patients with relapsed advanced non-small-cell lung cancer. Ann Oncol. 2011;22:1374-81.

14. Mross K, Stefanic M, Gmehling D, Frost A, Baas F, Unger C, et al. Phase I study of the angiogenesis inhibitor BIBF 1120 in patients with advanced solid tumors. Clin Cancer Res. 2010;16:311-9.

15. Bowen JM. Mechanisms of TKI-induced diarrhea in cancer patients. Curr Opin Support Palliat Care. 2013;7:162-7.

16. Fan L, Iseki S. Immunohistochemical localization of vascular endothelial growth factor in the endocrine glands of the rat. Arch Histol Cytol. 1998;61:17-28.

17. Wacker B, Nagrani T, Weinberg J, Witt K, Clark G, Cagnoni PJ. Correlation between development of rash and efficacy in patients treated with the epidermal growth factor receptor tyrosine kinase inhibitor erlotinib in two large phase III studies. Clin Cancer Res. 2007;13:3913-21.

18. Cohen EE, Halpern AB, Kasza K, Kocherginsky M, Williams R, Vokes EE. Factors associated with clinical benefit from epidermal growth factor receptor inhibitors in recurrent and metastatic squamous cell carcinoma of the head and neck. Oral Oncol. 2009;45:e155-60.

19. Chen HX, Cleck JN. Adverse effects of anticancer agents that target the VEGF pathway. Nat Rev Clin Oncol. 2009;6:465-77.

20. Schmidinger M. Understanding and managing toxicities of vascular endothelial growth factor (VEGF) inhibitors. EJC Suppl. 2013;11:172-91.

21. Collard HR, Ward AJ, Lanes S, Cortney Hayflinger D, Rosenberg DM, Hunsche E. Burden of illness in idiopathic pulmonary fibrosis. J Med Econ. 2012;15:829-35.

\section{Submit your next manuscript to BioMed Central and take full advantage of:}

- Convenient online submission

- Thorough peer review

- No space constraints or color figure charges

- Immediate publication on acceptance

- Inclusion in PubMed, CAS, Scopus and Google Scholar

- Research which is freely available for redistribution 